\title{
Sağlık Bilimleri Fakültesi Öğrencilerinin Kullandıkları Öğrenme Stratejilerinin İncelenmesi
}

\author{
Neslihan ALTUNTAŞ YLMAZ ${ }^{1}$ iD Mustafa AYDIN ${ }^{2}$ iD Musa ÇANKAYA M $^{3}$ \\ Mehmet Tuğrul YILMAZ4 ${ }^{4}$
}

${ }^{1}$ Necmettin Erbakan Üniversitesi, Sağlık Bilimleri Fakültesi, Fizyoterapi ve Rehabilitasyon Bölümü, Konya, Türkiye, yilmaz.altuntas.neslihan@gmail.com (Sorumlu Yazar/ Corresponding Author)

${ }^{2}$ Necmettin Erbakan Üniversitesi, AKEF, Eğitim Bilimleri Bölümü, Konya, Türkiye, maydinselcuk@ gmail.com

${ }^{3}$ Necmettin Erbakan Üniversitesi, Sağlık Bilimleri Fakültesi, Fizyoterapi ve Rehabilitasyon Bölümü, Konya, Türkiye, musa-cankaya@hotmail.com

${ }^{4}$ Necmettin Erbakan Üniversitesi, Meram Tıp Fakültesi, Temel Tıp Bilimleri Bölümü, Konya, Türkiye, mehmet_tugruly@yahoo.com

\begin{tabular}{|c|c|}
\hline Makale Bilgileri & ÖZ \\
\hline $\begin{array}{l}\text { Makale Geçmişi } \\
\text { Geliş: } 05.06 .2020 \\
\text { Kabul: } 16.07 .2020 \\
\text { Yayın: } 25.12 .2020\end{array}$ & $\begin{array}{l}\text { Giriş: Günümüzde gelişen bilgi kaynaklarına paralel olarak, bilginin nicel olarak artması bilgiye } \\
\text { ihtiyaç duyan bireylerin sahip olması gereken becerileri de artırmıştır. } \\
\text { Amaç: Bu çalışma Sağlık Bilimleri Fakültesindeki öğrencilerin öğrenme stratejilerini araştırmayı } \\
\text { amaçlamıştır. }\end{array}$ \\
\hline $\begin{array}{l}\text { Anahtar Kelimeler: } \\
\text { Öğrenme stratejileri, } \\
\text { Öğrenci, } \\
\text { Sağlık bilimleri. }\end{array}$ & $\begin{array}{l}\text { Yöntem: Necmettin Erbakan Üniversitesi Sağlık Bilimleri Fakültesi bünyesinde bulunan; } \\
\text { Beslenme ve Diyetetik, Hemşirelik ve Fizyoterapi ve Rehabilitasyon bölümlerinde öğrenim gören } \\
512 \text { ( } 346 \text { kı, } 166 \text { erkek) ögrenci çalışmaya dahil edilmiştir. } 67 \text { maddeden oluşan } \\
\text { Yükseköğretimde Öğrenme Stratejileri Ölçeği (LIST) kullanılarak veriler elde edilmiştir. } \\
\text { Bölümler arası farklılıklar ANOVA, cinsiyetler arası değerlendirmede Independent Samples Testi, } \\
\text { akademik başarıyı etkileyen öğrenme stratejisini ortaya koyabilmek amaciyla ise Corelasyon testi } \\
\text { yapılmıştır. Istatistiksel yanılma düzeyi p }<0,05 \text { olarak kabul edildi. } \\
\text { Bulgular: Öğrenme stratejilerinin cinsiyete göre farklılık gösterdiği, Kadınların organizasyon ve } \\
\text { kaynak kullanımını, erkeklerinde planlama stratejisini daha çok tercih ettikleri sonucu } \\
\text { bulunmuştur. Bölümler arasında anlamlı bir farklılık bulunmamıştır (P<0,05). Öğrencilerin } \\
\text { akademik başarısı ile organizasyon, çaba, zaman, örgütleme, eleştirel düşünce ve tekrar } \\
\text { stratejilerinde güçlü pozitif bir korelasyon bulunmuştur. } \\
\text { Sonuç ve Öneriler: Üniversitelerde eğitim programına ilave olarak öğrenme stratejilerinin } \\
\text { öğretilmesinin akademik müfredata ilave edilmesinin akademik başarıyı artıracağ1 sonucuna } \\
\text { ulaş1lmıştır. }\end{array}$ \\
\hline
\end{tabular}

Investigation of Learning Strategies of Faculty of Health Sciences Students

\begin{tabular}{ll}
\hline \hline Article Info & ABSTRACT \\
\hline $\begin{array}{l}\text { Article History } \\
\text { Received: } 05.06 .2020 \\
\text { Accepted: } 16.07 .2020 \\
\text { Published: } 25.12 .2020\end{array}$ & $\begin{array}{l}\text { Introduction: In parallel with the information sources developing today, the quantitative increase } \\
\text { of information has increased the skills that individuals who need information should have. } \\
\text { Objective: This study aimed to investigate the learning strategies of students in the faculty of } \\
\text { health sciences. } \\
\text { Keywords: }\end{array}$ \\
$\begin{array}{l}\text { Mearning strategy, } \\
\text { students studying in nutrition and dietetics, nursing and physiotherapy and rehabilitation } \\
\text { Student, }\end{array}$ & $\begin{array}{l}\text { departments were included in the study. Data were obtained using the Higher Education Learning } \\
\text { Strategies Scale (LIST) consisting of } 67 \text { items. Differences between departments ANOVA, } \\
\text { Independent Samples Test in gender assessment, Corelation test was performed in order to reveal } \\
\text { the learning strategy affecting academic success. Statistical error level was accepted as p <0.05. } \\
\text { Results: The findings of the study showed that the learning strategies used by the students of the } \\
\text { health sciences faculty were related to their gender and academic achievement. } \\
\text { Conclusions and Recommendations: It was concluded that teaching learning strategies in } \\
\text { addition to the curriculum in universities will add academic success to the curriculum. }\end{array}$
\end{tabular}

Atıf/Citation: Yılmaz, N.A., Aydın, M., Çankaya, M., Yılmaz, M.T. (2020). Sağlık bilimleri fakültesi öğrencilerinin kullandıkları öğrenme stratejilerinin incelenmesi. Genel Sağllk Bilimleri Dergisi, 2(3), 109-116. 


\section{GİRIŞ̧}

Günümüzde gelişen bilgi kaynaklarına paralel olarak, bilginin nicel olarak artması bilgiye ihtiyaç duyan bireylerin sahip olması gereken becerileri de artırmıştır. Bireylerin sözü edilen bu sürece uyum sağlayabilmeleri için eleştirel düşünme, problem çözme, karar verme vb. becerilerine sahip olmaları beklenir.

Bu becerilerin geliştirilmesi, yapılandırmacı yaklaşımın öngördüğü (Jaworski, 1994; Marlowe, Page, 1998; Von Glasersfeld, 1995; Woolfolk, 2004) öğrencinin öğrenme sürecinde aktif olduğu, kendi öğrenmesinin sorumluluğunu aldığı, kavramları kendi ön-bilgi ve öğrenme tercihlerine göre zihninde yapılandırdığı bir öğretim ortamının sunulmasıyla mümkün görülmektedir. Bu sayede öğrenmeyi öğrenmiş bireyler yetiştirmek mümkün olabilmektedir. Öğrenmeyi öğrenen bireyler kendi öğrenme özelliklerini bilerek öğrenmeleri için uygun stratejileri seçerek kullanabilirler ve etkili öğrenmeyi gerçekleştirirler (Özer, 1998).

Günümüz öğrenmesine damgasını vurmuş olan aktif öğrenme, öğrencilere kendi farkındalık düzeylerini yükseltme konusunda görevler yüklemiştir. Kendi düşünmelerinin farkında olmaya ek olarak bilişleri hakkında da daha fazla bilgi sahibi olmanın farkındalığını yükseltmek ve böylece en iyisini öğrenme eğiliminde olmak, kendi öğrenmesini kendisi sağlayan öğreniciler olabilme yolunu açmıştır.

Öğrenicinin kendi biliş, metabiliş ve öğrenme özelliklerinin farkında olması kadar motivasyon konusunda da farkındalık düzeyinin yükselmesini sağlamıştır (Sağırlı, 2009). Son yirmi yılda öz-düzenleme ile ilgili yapılan araştırma sayısı artmış, bu araştırmaların çoğu öğrenme stratejileri ve motivasyonel inançlar ile ders başarısı arasında pozitif yönde anlamlı bir ilişki olduğunu ortaya koymuştur.

Öğrenme stratejileri, bireylerin yaşam boyu okur yazar, üretici ve bağımsız birer öğrenen olmasını sağlar. Bunun yanı sıra, öğrenme stratejileri; öğrencilerin kendi düşüncelerine güvenmesi, bir işi yapmak için birden fazla yol olduğunu bilmesi, kendi yanlışlarını fark etmesi ve onları düzeltmesi, kendi öğrenmelerini ve davranışlarını değerlendirmesi, hafızasını güçlendirmesi, öğrenme düzeyini artırması, nasıl öğreneceğini bilmesi, kendi öğrenme sürecini geliştirmesi ve kendi öğrenmesinde daha fazla sorumluluk üstlenmesine katkı sağlar (Beckman, 2002).

Literatürde öğrencilerin bireysel özellikleri arasında yer alan öğrenme stratejileri, başarıyı etkileyen önemli bir değişken olarak ön plana çıkmaktadır (Liem, Lau, \& Nie, 2008; Schwinger, Steinmayr \& Spinath, 2009; Diseth, 2011). Öğrenme stratejisi, bireyin kendi kendine öğrenmesini kolaylaştıran tekniklerin her biridir. Öğrenme stratejileriyle, öğrencinin bilgiyi işleyerek ve kalıcı biçimde öğrenmesini sağlamak amaçlanır. Bu nedenle öğrenme stratejileri seçme, düzenleme ve bütünleştirme biçimini etkilemesi beklenen davranış ve düşüncelerden oluşur (Weinstein ve Mayer, 1986).

Değişik öğrenme stratejilerini kullanabilen ve yeni öğrenme stratejileri geliştirebilen öğrencilerin, kendi kendilerine etkili öğrenmeyi gerçekleştirebildikleri söylenebilir (Özer, 1998). Öğrenme stratejileri en genel haliyle; bilişsel stratejiler, biliş üstü stratejileri ve kaynak kullanım stratejileri olarak sınıflandırılır. Bilişsel stratejiler ana bileşeninde yer alan yineleme (tekrar), organize etme, örgütleme ve eleştirel düşünme stratejileri, bilişüstü stratejiler bileşeninde oluşturan; planlama, düzenleme ve kaynak yönetimi ana bileşenini oluşturan; zaman, çalışma ortamı, çaba yönetimi, akran iş birliği, kaynak kullanımı ve konsantrasyon faktörlerinden oluşmaktadır.

Öğrencilerin, öğrenme stratejilerini etkili bir biçimde kullanabilmeleri için öncelikli olarak onların öğrenme stratejilerinin belirlenmesi gerekmektedir. Öğrencilerin sahip oldukları öğrenme stratejilerinin belirlenmesinde farlı öğrenme stratejilerini belirleme ölçekleri bulunmaktadır.

Yükseköğretimde Öğrenme Stratejileri Ölçeği (LIST); Boerner ve ark. (2005) tarafından geliştirilen, Erben ve Aydın (2019) tarafından Türkçeye uyarlanan bu ölçek 12 öğrenme stratejisi ve 67 maddeden oluşmaktadır. Sırasıyla ölçekte bulunan statejiler; organizasyon (7 madde), çaba yönetimi (7 madde), 
planlama (4 madde), düzenleme (3 madde), konsantrasyon (6 madde), zaman yönetimi (4 madde), çalışma ortamı (6 madde), akran işbirliği (4 madde), literatür/ kaynak kullanımı (4 madde), örgütleme (8 madde), eleştirel düşünme (7 madde), yineleme (7 madde) boyutlarından oluşur.

\section{AMAÇ}

$\mathrm{Bu}$ çalışmanın Sağlık Bilimleri Fakültesindeki öğrencilerin öğrenme stratejilerini arasındaki tercih farklılıklarını, bu farklılığın cinsiyete göre, bölüme göre değişimini, akademik başarı ile öğrenme stratejisi arasında ilişkinin araştırılmasını amaçlamıştır.

\section{YÖNTEM}

\section{Araştırmanın Tipi}

Bu çalışma Sağlık Bilimleri Fakültesinin üç bölümünden; beslenme ve diyetetik, hemşirelik ve fizyoterapi ve rehabilitasyon bölümlerinde öğrenim gören öğrencilerin öğrenme stratejilerinin ve öğrenme güdülenmesini belirlenmesi amacı ile tanımlayıcı türde planlanmıştır.

\section{Araştırmanın Evreni ve Örneklemi}

Çalışmanın evrenini Necmettin Erbakan Üniversitesi Sağlık Bilimleri Fakültesi bünyesinde bulunan; beslenme ve diyetetik, hemşirelik ve fizyoterapi ve rehabilitasyon bölümlerinde öğrenim gören öğrenciler oluşturmaktadır. Çalışmanın örneklemini ise bu çalışmaya katılmayı kabul eden toplam üç bölümden 512 (346 kız, 166 erkek) öğrenci oluşturmaktadır (Tablo 1).

Tablo 1. Çalışmaya dahil edilen öğrencilerin bölümlere ve cinsiyete göre sayılarının gösterilmesi.

\begin{tabular}{lcccc}
\hline Bölüm adı & \multicolumn{2}{c}{ Cinsiyet } & Toplam \\
\cline { 3 - 3 } Beslenme ve Diyetetik & Erkek & Kadın & 127 \\
Hemşirelik & 37 & 90 & 134 \\
Fizyoterapi ve Rehabilitasyon & 46 & 88 & 251 \\
Toplam & 83 & 168 & 512 \\
\hline
\end{tabular}

\section{Veri Toplama Araçları}

Çalışmaya katılmayı kabul eden öğrencilerde Yükseköğretimde Öğrenme Stratejileri Ölçeği (LIST) kullanılarak veriler elde edilmiştir.

\section{Veri Toplama}

Veri toplamada kullanılan ölçek, öğrencilere dağıtılmış olup formların yanıtlanması yaklaşık 15-20 dakika sürmüştür.

\section{Verilerin Analizi}

Araştırmaya katılan öğrencilerin akademik başarıları genel not ortalamalarına göre değerlendirilmiştir. Elde edilen veriler SPSS proğramına yüklenerek değerlendirilmiştir. Bölümler arası farklılıklar ANOVA, cinsiyetler arası değerlendirmede Independent Samples Testi, akademik başarıyı etkileyen öğrenme stratejisini ortaya koyabilmek amacıyla ise Corelasyon testi yapılmıştır. İstatistiksel yanılma düzeyi $\mathrm{p}<0,05$ olarak kabul edildi.

\section{BULGULAR}

Elde edilen bulgulara göre, Sağlık Bilimleri Fakültesi öğrencilerinin kullandıkları öğrenme stratejilerinden; organizasyon, planlama ve kaynak kullanımlarının öğrenci cinsiyetlerine göre anlamlı bir farklılık tespit edilmiştir $(\mathrm{p}<0,05)$ (Tablo 2).

Çalışmamızda, Sağlık bilimleri fakültesi öğrencilerinin kullandıkları öğrenme stratejilerinin hiçbirinde bölümlere göre anlamlı bir farklılığı saptanmamıştır $(\mathrm{p}<0,05)$ (Tablo 3). 
Tablo 2. Çalışmaya dahil edilen öğrencilerin öğrenme stratejileri ile cinsiyetleri arasındaki ilişkinin gösterilmesi.

\begin{tabular}{|c|c|c|c|c|c|}
\hline Öğrenme stratejisi & Cinsiyet & $\mathbf{N}$ & Ortalama & Ss & $\mathbf{P}$ \\
\hline \multirow[t]{2}{*}{ Organizasyon } & 1 & 166 & 29,2279 & 6,85082 & 0,00 \\
\hline & 2 & 346 & 32,0331 & 6,37322 & \\
\hline \multirow[t]{2}{*}{ Çaba Yönetimi } & 1 & 166 & 28,4201 & 6,98226 & 0,541 \\
\hline & 2 & 346 & 28,8726 & 6,60182 & \\
\hline \multirow[t]{2}{*}{ Planlama } & 1 & 166 & 13,1346 & 4,17403 & 0,02 \\
\hline & 2 & 346 & 12,2049 & 3,74623 & \\
\hline \multirow[t]{2}{*}{ Düzen } & 1 & 166 & 12,3597 & 3,71763 & 0,153 \\
\hline & 2 & 346 & 12,8589 & 2,99066 & \\
\hline \multirow[t]{2}{*}{ Konsantrasyon } & 1 & 166 & 20,4862 & 7,36942 & 0,573 \\
\hline & 2 & 346 & 20,9648 & 7,74267 & \\
\hline \multirow[t]{2}{*}{ Zaman Yönetimi } & 1 & 166 & 14,0490 & 5,03331 & 0,749 \\
\hline & 2 & 346 & 13,8693 & 5,07002 & \\
\hline \multirow[t]{2}{*}{ Çalışma Ortamı } & 1 & 166 & 26,4407 & 6,08447 & 0,386 \\
\hline & 2 & 346 & 27,0109 & 5,90878 & \\
\hline \multirow[t]{2}{*}{ Akran İşbirliği } & 1 & 166 & 17,2200 & 4,49930 & 0,77 \\
\hline & 2 & 346 & 18,0880 & 4,03017 & \\
\hline \multirow{2}{*}{ Kaynak Kullanımı } & 1 & 166 & 17,1538 & 4,63046 & 0,02 \\
\hline & 2 & 346 & 18,2079 & 4,27565 & \\
\hline \multirow[t]{2}{*}{ Örgütleme } & 1 & 166 & 35,4590 & 6,89297 & 0,600 \\
\hline & 2 & 346 & 35,8789 & 7,30256 & \\
\hline \multirow[t]{2}{*}{ Eleştirisel Düşünme } & 1 & 166 & 29,6092 & 7,22219 & 0,229 \\
\hline & 2 & 346 & 28,7349 & 6,39198 & \\
\hline \multirow[t]{2}{*}{ Tekrar } & 1 & 166 & 30,3625 & 7,60126 & 0,427 \\
\hline & 2 & 346 & 30,9841 & 6,93351 & \\
\hline
\end{tabular}

*1. Erkek, 2.Kadın, N: kişi sayısı, $\mathrm{P}<0,05$

Tablo 3. Sağllk bilimleri fakültesi öğrencilerinin kullandikları öğrenme stratejilerinin, bölümlere göre gösterimi.

\begin{tabular}{|c|c|c|c|c|c|}
\hline & Bölüm & Ortalama \pm SS & Minimum & Maksimum & $\mathbf{P}$ \\
\hline \multirow[t]{3}{*}{ Organizasyon } & 1 & $30,95 \pm 6,05$ & 7 & 42 & 0,422 \\
\hline & 2 & $31,76 \pm 5,97$ & 7 & 42 & \\
\hline & 3 & $30,46 \pm 5,06$ & 7 & 42 & \\
\hline \multirow[t]{3}{*}{ Çaba Yönetimi } & 1 & $27,45 \pm 6,93$ & 8 & 40 & 0,159 \\
\hline & 2 & $28,48 \pm 7,16$ & 7 & 42 & \\
\hline & 3 & $28,56 \pm 6,85$ & 9 & 42 & \\
\hline \multirow[t]{3}{*}{ Planlama } & 1 & $12,96 \pm 3,25$ & 6 & 24 & 0,098 \\
\hline & 2 & $12,58 \pm 3,78$ & 4 & 24 & \\
\hline & 3 & $12,25 \pm 3,48$ & 2 & 24 & \\
\hline \multirow[t]{3}{*}{ Düzenleme } & 1 & $12,15 \pm 3,16$ & 3 & 18 & 0,382 \\
\hline & 2 & $12,29 \pm 3,17$ & 3 & 18 & \\
\hline & 3 & $12,85 \pm 3,56$ & 3 & 18 & \\
\hline \multirow{3}{*}{ Konsantrasyon } & 1 & $20,16 \pm 7,18$ & 7 & 36 & 0,937 \\
\hline & 2 & $20,68 \pm 7,01$ & 6 & 36 & \\
\hline & 3 & $20,26 \pm 7,19$ & 6 & 36 & \\
\hline \multirow[t]{3}{*}{ Zaman Yönetimi } & 1 & $13,91 \pm 5,39$ & 4 & 24 & 0,945 \\
\hline & 2 & $13,19 \pm 5,36$ & 4 & 24 & \\
\hline & 3 & $13,51 \pm 5,29$ & 4 & 24 & \\
\hline \multirow[t]{3}{*}{ Çalışma Ortamı } & 1 & $27,56 \pm 5,45$ & 7 & 36 & 0,452 \\
\hline & 2 & $26,85 \pm 5,98$ & 8 & 36 & \\
\hline & 3 & $26,25 \pm 5,66$ & 6 & 36 & \\
\hline \multirow{3}{*}{ Akran İşbirliği } & 1 & $18,22 \pm 5,13$ & 6 & 24 & 0,191 \\
\hline & 2 & $17,99 \pm 5,16$ & 4 & 24 & \\
\hline & 3 & $18,16 \pm 5,49$ & 4 & 24 & \\
\hline
\end{tabular}




$\begin{array}{llllll}\text { Kaynak } & 1 & 18,85 \pm 4,68 & 5 & 24 & 0,228 \\ \text { Kullanımı } & 2 & 17,78 \pm 4,11 & 5 & 24 & 24 \\ \text { Örgütleme } & 3 & 18,65 \pm 4,95 & 4 & 48 & 0,086 \\ & 1 & 34,94 \pm 7,13 & 8 & 48 & 0,565 \\ \text { Eleştirel } & 2 & 35,18 \pm 7,09 & 9 & 48 & 42 \\ \text { Düşünme } & 3 & 35,08 \pm 7,89 & 8 & 42 & 0,613 \\ \text { Tekrar } & 1 & 28,99 \pm 6,76 & 7 & 42 & 42 \\ & 2 & 29,21 \pm 6,43 & 7 & 8 & 42 \\ \end{array}$

*1. Beslenme ve Diyetetik, 2. Hemşirelik, 3. Fizyoterapi ve Rehabilitasyon Bölümleri

Sağlık Bilimleri Fakültesi öğrencilerinin kullandıkları Öğrenme Stratejileri ve Akademik Başarıları arasında ilişki incelendiğinde, öğrencilerin notları ile organizasyon, çaba, zaman, örgütleme, eleştirel düşünce ve tekrar stratejilerinde güçlü pozitif bir korelasyon bulunmuştur.

\section{TARTIŞMA}

Cinsiyetlere göre öğrenme stratejilerine bakıldığı zaman; organizasyon, planlama ve kaynak kullanımı stratejilerinin cinsiyetlere göre anlamlı farklılı̆̆ı dikkat çekmiştir. Kadınların organizasyon ve kaynak kullanımını, erkeklerinde planlama stratejisini daha çok tercih ettikleri sonucu bulunmuştur. Diğer öğrenme stratejilerilerin tercihinde cinsiyetlere göre anlamlı bir farklılık saptanmamıştır. Sağırlı ve Azapağası (2009) yaptıkları çalışmada bu çalışmanın aksine cinsiyetin farklılık yaratan bir değişken olmadığı sonuçlarına ulaşmışlardır. Literatürde bizim çalışmamızı destekleyen (Wolters ve Pintrich, 1998) ve desteklemeyen (Alcı ve Altun, 2007; Peklaj ve Pecjak, 2002) farklı araştırmalara rastlanmıştır.

Yağlı (2014) yaptığı çalışmada farklı bölümlerdeki öğrencilerin kullandıkları öğrenme stratejilerinin bölümlere göre farklılık göstermediği sonucuna ulaşmışlardır. Çalışmamızda Yağlı'nın çalışmasına benzer şekilde 3 bölüm arasında anlamlı bir farklılığa rastlanmamıştır.

Namlu (2004) Bilişötesi öğrenme stratejileri ölçeğini kullanarak üniversite öğrencilerin başarılarını incelediği çalışmada öğrenci başarıları ile ilgili en kuvvetli faktör olarak bulunan planlama stratejileri olduğu sonucuna ulaşmıştır. Özellikle öğrenmeye yönelik ders çalışma programı hazırlama, işlerini zamanında yapma, önceden hazırlık için gerekli koşulları sağlama ve derse ilişkin zihinsel hazırlık yapma stratejileri bu grupta toplanmıştır. Bizim elde ettiğimiz sonuçlara göre öğrenci not başarısı ile planlama faktörü arasında bir korelasyon görülmemiştir.

Ders çalışmaya başlarken zihni hazırlama stratejileri olarak yer alan örgütleme stratejisi Namlu ve ark (2004)'larına göre başarıyı etkileyecek ikinci faktördür. Özellikle, öğrenilecek bilginin zihinde yer alan bilişötesi şemalara göre önceden belirlenerek çalışılmasını işaret etmektedir. Herhangi bir öğrenme etkinliği için önceden konu başlıklarının ve anahtar kavramların belirlenmesi, bunun için öğrenilecek içeriğin gözden geçirilmesini ifadelendiren örgütleme stratejileri bilişötesi öğrenmede önemli bir yere sahip olduğunu göstermektedir. Bizim de çalışmamız bu sonucu destekler nitelikte olup, başarı notu ile örgütleme statejisi arasında pozitif korelasyon bulunmuştur.

Araştırma bulguları kapsamında, öğrencilerin akademik başarı düzeyleri ile öğrenme stratejileri arasında anlamlı ilişkiler olduğu görülmektedir. Bu sonuç Bal (2012), Gülümbay (2005), Saracaloğlu \& Karasakaloğlu (2011) ve Yalçın'ın (2003) çalışmalarıyla da paralellik göstermektedir.

\section{SONUÇ ve ÖNERILER}

$\mathrm{Bu}$ araştırmada öğrenme stratejilerinin cinsiyete göre farkl1lık gösterdiği, sağlık bilimleri fakültesinin; beslenme ve diyetetik, hemşirelik ve fizyoterapi ve rehabilitasyon bölümlerine göre anlamlı bir farklılık göstermediği sonucuna ulaşılmıştır. Öğrencilerin akademik başarısını ile organizasyon, çaba, zaman, örgütleme, 
eleştirel düşünce ve tekrar stratejilerinde güçlü pozitif bir korelasyon bulunmuştur.

Bilgi çağının yaşandığı günümüzde; bilgi toplumunun oluşturulabilmesi için, bilgiyi nasıl öğreneceğini bilen, öğrenme sürecini kontrol edebilen, öğrenmeyi öğrenen bireylere ihtiyaç duyulmaktadır. Eğitim kurumlarının en önemli işlevi eğitimli ve üretken bireyler yetiştirerek toplumun gelişmesini ve sürekliliği sağlamaktır. Bu çerçevede çalışmamızın üniversitelerin eğitim programlarının paralelinde öğrencilere öğrenme stratejilerinin öğretilmesinin hedeflenen birey tipine ve toplum yapısına ulaşmaya katkı sağlayacağ çalışmayı düşünen akademisyenler için yol gösterici olduğunu düşünmekteyiz.

\section{Finansal destek}

Finansal destek alınmamıştır.

\section{Çıkar çatışması}

Yazarlar arasında herhangi bir çıkar çatışması yoktur.

\section{Yazarlık Katkıları:}

Tasarım/Design: N.A.Y.; Veri toplama veya Veri Girişi Yapma/Data Collection or Processing: M.Ç.;

Analiz ve Yorum/ Analysis and Interpretation: M.A.; Literatür Tarama/Literature Search: M.T.Y.; Yazma/Writing: N.A.Y.

\section{KAYNAKÇA}

Jaworski, B. (1994). Investigating mathematics teaching: A constructivist inquiry. Investigating Mathematics Teaching. London: The Falmer Press.

Marlow, BA., Page, ML. (1998). Creating and Sustaining the Constructivist Classroom. Thousand Oaks, CA: Corwin Press.

Von Glasersfeld, E. (1995). A constructivist approach to teaching. In L. Steffe, \& J. Gale (Eds.), Constructivism in education (pp. 3-16).

Woolfolk, A. (2004). Educational psychology. Boston, MA: Pearson.

Özer, B. (1998). Eğitim Bilimlerinde Yenilikler İçinde A. Hakan (Ed.) Öğrenmeyi öğretme. Eskişehir: Anadolu Üniversitesi, Açıköğretim Fakültesi, No:55, 147-162.

Sağırlı, ÖM., Azapağası, E. (2009). Investigation of Self-Regulated Learning Abilities of College Students. Ankara University, Journal of Faculty of Educational Sciences, 42, (2), 129-161. https://doi.org/10.1501/Egifak_0000001180.

Beckman, P. (2002). Strategy instruction. ERIC Digest (ED 474302). Arlington, VA: ERIC Clearinghouse on Disabilities and Gifted Education.

Liem, AD., Lau, S., Nie, Y. (2008). The role of self-efficacy, task value, and achievement goals in predicting learning strategies, task disengagement, peer relationship, and achievement outcome. Contemporary Educational Psychology, 33, 486-512. http://dx.doi.org/10.1016/j.cedpsych.2007.08.001

Steinmayr, R., Weidinger, Af., Schwinger, M., Spinath, B. (2019). The Importance of Students' Motivation for Their Academic Achievement-Replicating and Extending Previous Findings. Front Psychol, 10, 1-11. https://doi.org/10.3389/fpsyg.2019.01730

Diseth, A.. (2011). Self-efficacy, goal orientations and learning strategies as mediators between preceding and subsequent academic achievement. Learning and Individual Differences, 21(2), 191-195. http://dx.doi.org/10.1016/j.lindif.2011.01.003.

Weinstein, CE. \& Mayer, RE. (1986). The teaching of learning strategies. İçinde M.C. Wittrock (Ed.) Handbook of research on teaching, (3rd. Edition). New York: Macmillan Company.

Boerner, S., Seeber, G., Keller, H., \& Beinborn, P. (2005). Lernstrategien und lernerfolg im studium. Zeitschrift für Entwicklungspsychologie und Pädagogische Psychologie, 37(1), 17-26. https://dx.doi.org/10.1026/0049-8637.37.1.17

Erben, S., Aydın, M. (2019). The Adaptation of Learning Strategies for Higher Education Scale for Turkish Context. International Journal of Instruction, 12 (1), 1413-1430. https://doi.org/10.29333/iji.2019.12190a.

Wolters, CA., Pintrich, PR. (1998). Contextual differences in student motivation and self-regulated learning in mathematics, English, and social studies classrooms. Instructional Science, 26: 27-47. https://doi.org/10.1023/A:1003035929216 .

Alc1, B., Altun, S. (2007). Lise öğrencilerinin matematik dersine yönelik özdüzenleme ve bilişüstü becerileri, cinsiyete, sınıfa ve alanlara göre farklılaşmakta mıdır? Çukurova Üniversitesi Sosyal Bilimler Enstitüsü Dergisi, 16 (1). 
Peklaj, C., Pecjak, S. (2002). Differences in students' self-regulated learning according to their achievement and sex. Studia psychologica, 44(1):29-43.

Yağlı, Ü. (2014). İngilizce dersinde öğrenmede kullanılan öz-düzenleme stratejileri ve başarı ile ilişkisi. Karaelmas Eğitim Bilimleri Dergisi, 2(1), 108-116.

Namlu, AG. (2004). Bilişötesi öğrenme stratejileri ölçme aracının geliştirilmesi: geçerlilik ve güvenirlik çalışması. Anadolu Üniversitesi Sosyal Bilimler Dergisi, 2, 123-136.

Bal, AP. (2013). Investigating Undergraduate Students' Assessment Preferences in Mathematics Course and Learning Strategies. International Online Journal of Educational Sciences, 5 (1), 242-257.

Gülümbay, AA. (2005). Yükseköğretimde web’e dayalı ve yüzyüze ders alan öğrencilerin öğrenme stratejilerinin, bilgisayar kaygılarının ve başarı durumlarının karşılaştırılması. Yayınlanmamış doktora tezi, Anadolu Üniversitesi Eğitim Bilimleri Enstitüsü, Eskişehir.

Saracaloğlu, SA., Karasakaloğlu, N. (2011). Sınıf Öğretmeni Adaylarının Okuduğunu Anlama Düzeyleri ile Çalışma ve Öğrenme Stratejilerinin Çeşitli Değişkenler Açısından İncelenmesi. Eğitim ve Bilim Dergisi, 36 (161), 98-115.

Yalçı, E. (2003). An analysis of the relationship between the use of grammar learning strategies and student achievement at English preparatory school at the university of Gaziantep. Unpublished Master's thesis, The University of Gaziantep, Gaziantep 


\section{EXTENDED ABSTRACT}

Objective: In parallel with the information sources developing today, the quantitative increase of information has increased the skills that individuals who need information should have. In order for individuals to adapt to this process, critical thinking, problem solving, decision making etc. they are expected to have the skills.. Learning strategies, which are among the individual characteristics of students in the literature, come to the fore as an important variable affecting success.

Learning strategies are aimed at ensuring that the student learns by processing information and permanently. For this reason, learning strategies consist of behaviors and thoughts that are expected to affect the way you choose, organize, and integrate. In order for students to be able to use learning strategies effectively, first of all, their learning strategies should be determined. There are scales for determining different learning strategies in determining the learning strategies that students have.

This study aimed to investigate the differences between the learning strategies of students at the Faculty of Health Sciences, the difference between this difference by gender, by department, and the relationship between academic success and learning strategy.

Methods: Necmettin Erbakan University Faculty of Health Sciences; Learn in nutrition and dietetics, nursing and physiotherapy and rehabilitation departments. 512 departments (346 girls, 166 boys) students work. Data were obtained by using the Higher Education Learning Strategies Scale (LIST) among the students who agreed to participate in the study.

Learning Strategies Scale in Higher Education (LIST); Boerner et al. (2005) and adapted to Turkish by Erben and Aydin (2019), this scale consists of 12 learning strategies and 67 items. Statejies not found, respectively; organization (7 items), management management ( 7 items), planning (4 items), regulation (3 items), seven (6 items), time management (4 items), work environment (6 items), peer collaboration (4 items) ), literature / resource use (4 items), organization (8 items), critical thinking (7 items), repetition (7 items).

The academic success of the students participating in the research was evaluated according to their GPA. The obtained data were evaluated by uploading them to the SPSS program. Differences between departments ANOVA, Independent Samples Test in gender assessment, Corelation test was performed in order to reveal the learning strategy affecting academic success. Statistical error level was accepted as $\mathrm{p}<0.05$.

Results: According to the findings, the learning strategies used by the students of the Faculty of Health Sciences; There was a significant difference between organization, planning and resource use according to student gender $(\mathrm{P}<0.05)$. When the relationship between the Learning Strategies and Academic Achievements used by the Faculty of Health Sciences students was examined, a strong positive correlation was found in the grades of the students in their organization, effort, time, organization, critical thinking and repetition strategies.

The organizing strategy, which takes place as mind preparation strategies when starting to study, is an important factor that will affect success. In particular, it indicates that the information to be learned should be determined beforehand according to the metacognitive schemes in the mind. Identifying topics and key concepts in advance for any learning activity, and organizing strategies that express the review of the content to be learned, show that they have an important place in metacognitive learning. Our study also supports this result, and a positive correlation was found between success grade and organizing strategy.

Conclusions and Recommendations: When looking at learning strategies by gender; Significant differences in organization, planning and resource utilization strategies according to gender were noted. It was found that women prefer organization and resource use more than men and planning strategy. No significant difference was found in the choice of other learning strategies by gender.

In this research, it was found out that the faculty of health sciences, where learning strategies differ by gender; It is concluded that there is no significant difference in terms of nutrition and dietetics, nursing and physiotherapy and rehabilitation departments. A strong positive correlation was found in the academic achievement of the students in organization, effort, time, organization, critical thinking and repetition strategies.

In today's information age; In order to create an information society, individuals who know how to learn information, who can control the learning process, and who learn to learn are needed. The most important function of educational institutions is to ensure the development and continuity of the society by raising educated and productive individuals. In this framework, we think that teaching learning strategies to students in parallel with the educational programs of universities will contribute to the targeted individual type and social structure, and that it is a guide for academics who are considering working in this field. 